\title{
Spatial Distribution of Stunting and Its Associated Factors Among Under-five Children in Ethiopia: Spatial and Multilevel Analysis
}

Delelegn Emwodew Yehualashet ( $\sim$ delelegn1244@gmail.com )

Dilla University https://orcid.org/0000-0001-9899-555X

\section{Binyam Tariku Seboka}

Dilla University

Getanew Aschalew Tesfa

Dilla University

\section{Elias Seid}

Jimma University

\section{Samuel Hailegebreal}

Arbaminch University

Abel Desalegn Demeke

Dilla University

Endris Seid Amede

Dilla University

\section{Research}

Keywords: Stunting, Spatial, Multilevel, Individual factors, Community factors, Under-five children, Ethiopia

Posted Date: October 28th, 2021

DOI: https://doi.org/10.21203/rs.3.rs-990384/v1

License: (c) (1) This work is licensed under a Creative Commons Attribution 4.0 International License. Read Full License 


\section{Abstract}

Background: Childhood stunting is a major challenge to the growth and development of nations by affecting millions of children across the world. Although Ethiopia has made steady progress in reducing stunting, the prevalence of stunting is still one of the highest in the world. This study aimed to assess the spatial variation and factors associated with stunting among under-five children in Ethiopia.

Methods: This study is a secondary data analysis of the 2019 Ethiopian Mini Demographic and Health Survey (EMDHS). The Getis-Ord statistics tool has been used to identify areas with high and low hotspots of stunting. A multilevel logistic regression model was used to identify factors associated with stunting. Adjusted odds ratios (AOR) with its $95 \%$ confidence intervals $(\mathrm{Cl})$ at $\mathrm{p}$-value $<0.05$ were used to declare statistical significance.

Results: The result of this study shows that about $37 \%$ of under-five children were stunted. Statistically significant hotspots of stunting were found in northern parts of Ethiopia. Children in the age group between 24-35 months were more likely to be stunted than children whose age was less than one year [AOR = 3.74; $95 \% \mathrm{Cl}$ : (3.04-4.59)]. Children with mothers who had completed higher education had lower odds of being stunted compared to children whose mothers had no formal education [AOR $=0.55 ; 95 \% \mathrm{Cl}$ : (0.38-0.82)]. Children from the poorest wealth quintile had higher odds of being stunted compared to children from the richest wealth quintiles [AOR $=2 ; 95 \% \mathrm{Cl}$ : (1.46-2.73)]. Children living in Tigray (AOR =3.64; 95 \% Cl: 2.17-6.11), Afar (AOR 2.02; 95 \% Cl 1.19-3.39), Amhara (AOR =2.29; 95 \% Cl: 1.37-3.86), Benishangul Gumz (AOR=1.87; 95\% $\mathrm{Cl}: 1.10-3.17)$ and Harari (AOR=1.95; 95\% $\mathrm{Cl}$ : 1.17-3.25) regions were more likely to be stunted compared to children living in Addis Ababa.

Conclusion: This study showed that both individual and community-level factors were significant predictors of stunting. Improving maternal education, improving the economic status of households, improving age-specific child feeding practice, and providing additional resources to regions with high hotspots of stunting are recommended.

\section{Introduction}

Stunting has been defined as "poor growth and development of children due to malnutrition, frequent infections and insufficient psychosocial motivation" [1]. Height for the Z-score is a growth score over the years that can be used as an indicator of growth retardation and cumulative growth deficit in children. Children whose Z-score of growth at age below minus two standard deviations (-2 SD), which is the median of the reference population, are considered short for their age (stunted) [1]. Stunting affects many children worldwide and has serious short-term and long-term health consequences, including poor cognitive performance, lower educational performance, lower adult wages, and lower reproductive outcomes [2, 3].

Childhood stunting varies in size and distribution in different parts of the world. Global prevalence ranges from the highest (35.2\%) in East and Central Africa to the lowest (2.6\%) in North America [4]. Although 
Ethiopia has made steady progress in reducing stunting (the prevalence of stunting has dropped from $51-37 \%$ since 2005-2019), the prevalence of stunting is still the highest in the world and remains a serious public health problem within the country [5]. Numerous studies have shown that child sex, child age, maternal education, father education, maternal occupation, household income, maternity care service utilization, drinking water sources, type of toilet facilities, number household members, feeding practices, residence, and region were significant predictors of childhood stunting [6-11].

Various policies, programs, and strategies are being implemented around the world to reduce the problem of childhood stunting. The Global Nutrition Goal 2025 [12], approved by the Sixty-fifth World Health Organization Assembly in 2012, reduced the number of stunted children by $40 \%$ [13, 14]. Ethiopia is implementing the National Nutrition Program Phase I (2010-2015) and Phase 2 (2016-2020), which aims to reduce childhood stunting in children under the age of five [15].

Despite these interventions, the stunting rate among children in Ethiopia is still high. Furthermore, previous studies used old and outdated data that did not reflect the current situation in the country, and these studies were limited to small areas to indicate a national problem. Thus, this study aimed to assess the spatial distribution of stunting and its associated factors in children under the age of five in Ethiopia using national representative data from the recent National Demographic and Health Survey. The results of this study will help health care programs and policymakers to initiate appropriate policies and programs to reduce malnutrition-related deaths in the country.

\section{Methods}

\section{Study design and setting}

The study used data from the 2019 Ethiopian Mini-Demographic and Health Survey (EMDHS). The 2019 EMDHS is a population-based household survey conducted in Ethiopia from March 21 to June 28, 2019. Ethiopia is located in the North-Eastern part of Africa or known as the "Horn of Africa." It is bounded by the north and south Sudan on the west, Eritrea and Djibouti to the northeast, Somalia to the east and southeast, and Kenya to the south. Ethiopia lies between the $3^{\circ} \mathrm{N}$ and $15^{\circ} \mathrm{N}$ Latitude and $33^{\circ} \mathrm{E}$ and $48^{\circ} \mathrm{E}$ Longitude.

\section{Sampling procedure}

EMDHS 2019 uses the two-step stratified cluster sampling method in which sample households have chosen within clusters EAs (Enumeration areas). At the first stage, a total of 305 EAs were selected (93 live in urban areas and 212 in rural areas) with a probability proportional to the size of the EA and with independent selection in each sampling stratum. At the second stage of selection, a fixed number of 30 households in each cluster were selected, along with the probability of systematic selection of newly formed houses in the list. For our study, a total weighted sample of 4,971 children was used in the final analysis.

\section{Measurements}


The 2019 EMDHS collected data on the nutritional status of children by measuring the weight and height of children under age 5 . The length of children aged $<24$ months were measured lying down on the board (recumbent length), while children $\geq 24$ months were measured standing up. The height-for-age Z-score, an indicator of nutritional status, as compared with reference data from the WHO Child Growth Standards reference population, 2006. Children whose height-for-age Z-score is $<-2$ SD from the median of the WHO reference population are considered stunted (short for their age). Any additional information about data collection, sampling, and questionnaires used in the survey are described in detail in the 2019 EMDHS report [5].

\section{Study variables}

The outcome variable for this study was stunting, which is dichotomized as stunted (if height-for-age $Z$-score <-2 SD from the median of the reference population) and normal (if height-for-age Z-score >= -2 SD from the median of the reference population). Both individual and community-level factors were considered as the potential predictor variables. The individual-level factors included were child age, child sex, maternal education, wealth index, number of under-five children in the household, type of birth, and preceding birth interval. The four variables place of residence, region, type of latrine facility, and source of drinking water were considered as community-level factors.

\section{Data management and analysis}

Data cleaning was carried out to check for consistency. Data analysis was done using STATA version 14.2 and spatial analysis was done using ArcGIS software, version 10.8. Sample weights were done to adjust for non-proportional allocation of the sample to strata and regions during the survey process and to restore representativeness. Descriptive and summary statistics were conducted to describe the study population. A multi-level logistic regression analysis was carried out to account for the hierarchal nature of the DHS data.

\section{Spatial analysis}

ArcGIS 10.7 software was used for spatial analysis of the data. Spatial autocorrelation (Global Moran's I) statistics and Getis-Ord local cluster analysis were done to display the spatial distribution of childhood stunting in Ethiopia. The spatial Autocorrelation (Global Moran's I) is a tool used to verify whether childhood stunting is spatially clustered, dispersed or randomly distributed in Ethiopia. The tool calculates Moran's I Index value and both Z score \& p-value to evaluate the significance of the index. Moran's I index close to -1 indicates dispersing of childhood stunting whereas, close to 1 indicates clustering. Statistically significant Z-score and P-value $\leq 0.05$ lead to rejection of the null hypothesis showing the existence of clusters stunting[16]. Statistically non-significant Moran's I value (if $p$-value > 0.05 ) will indicate stunting is randomly distributed throughout the country [16].

The spatial heterogeneity of significant-high prevalence/low prevalence areas of stunting was computed for each cluster using the Getis-Ord G-statistic tools. The Local Getis-Ord G index helped to classify the autocorrelations into positive and negative correlations. If prevalence rates had similarly high values or 
low values, they were defined as positive autocorrelation hotspots (represented as High- High or Low-Low autocorrelation). If the attributes held opposing high and low values, they were considered to have negative autocorrelation (represent as High-Low or Low-High autocorrelation) [16]. To determine the significance of these statistics, Z-scores and P-values were used. A positive Z-score with a P-value of $<0.05$ indicates statistical clustering of hotspots of childhood stunting whereas a negative Z-score with a $p$-value of $<0.05$ indicates statistical clustering of children who are not stunted.

Kuldorff's Sat Scan version 9.4 software was used to identify the geographical locations of statistically significant clusters of stunting. Bernoulli's model was fitted to identify statistically significant locations of clusters. The Bernoulli model was selected because the structure of the data shows the binomial [0/1] distribution. The stunted child was considered as a case and labelled 1 whereas; normal child controlled and labelled 0 . The default $50 \%$ of the population was used as an upper limit for cluster size; because it allows the detection of both small and large clusters of stunting. Statistically significant clusters were identified by P-value and likelihood ratio tests.

\section{Multilevel analysis}

Multivariable multilevel logistic regression was used to analyze factors associated with childhood stunting at two levels: individual and community (cluster) levels. Four models were fitted for this multilevel logistic regression analysis. The first model was an empty model without any explanatory variables to evaluate the extent of the cluster variation on stunting, the second model with individual-level variables, the third model with community-level variables, and the fourth model with both the individualand community-level variables. A P-value of $<0.05$ was used to define statistical significance. Adjusted Odds Ratios (AOR) with their corresponding $95 \%$ confidence intervals ( $\mathrm{Cls}$ ) was calculated to identify the independent predictors of stunting. We used the Bayesian Deviance Information Criterion (DIC) as a measure of the goodness of fit of the models. Intra-class correlation coefficient (ICC), proportional change in variance (PCV), and median odds ratio (MOR) were calculated to measure the variation between clusters.

\section{Results}

\section{Characteristics of participants}

A total of 4,971 children were included in this study. Almost half of these children were females $(49 \%$; $2441 / 4971)$. Over half $(53.60 \% ; 2665 / 2971)$ of mothers were not educated. The poorest wealth quintile comprises about $22.97 \%$ (1140/4971) of the total population. A total of $20.12 \%(1000 / 4971)$ of the children were infants less than a year and 74.88\% (3722/4971) were from rural areas. Most of the children $(83.67 \% ; 4160 / 4971)$ had a preceding birth interval of 24 months and above.

The prevalence of childhood stunting was $37 \%(95 \% \mathrm{Cl}: 34.53,39.25)$. About $40.04 \%$ of stunted children were males, $45.45 \%$ of them were aged $24-35$ months, and $40.62 \%$ lived in rural areas. The proportion of 
stunted children were found higher among children in the Tigray region (49\%), having $<24$ months of birth interval (42.66\%), no education of mother (41.68\%), and poorest wealth index (42.63\%). Moreover, more than half $(57.41 \%)$ of children with multiple birth types were stunted. Table 1 
Table 1

Socio-demographic characteristics of children under age 5 in Ethiopia, EMDHS 2019

\begin{tabular}{|c|c|c|c|}
\hline Variables & Total n (\%) & Stunted n (\%) & Normal n (\%) \\
\hline \multicolumn{4}{|l|}{$\begin{array}{l}\text { Age of a child } \\
\text { (months) }\end{array}$} \\
\hline \multirow{2}{*}{ 6-11 } & $1,000(20.12)$ & $221(22.1)$ & 779 (77.9) \\
\hline & $1,005(20.22)$ & $327(32.64)$ & 677 (67.36) \\
\hline $12-23$ & 979 (19.70) & $445(45.45)$ & $534(54.54)$ \\
\hline $24-35$ & $1,042(20.95)$ & $427(41.02)$ & $614(58.98)$ \\
\hline $36-47$ & 945 (19.05) & $411(43.49)$ & 534 (43.49) \\
\hline \multicolumn{4}{|l|}{$48-59$} \\
\hline \multicolumn{4}{|l|}{ Child sex } \\
\hline Female & $2,441(49.11)$ & 819 (35.55) & $1,622(66.45)$ \\
\hline Male & $2,530(50.89)$ & $1,013(40.04)$ & $1,517(59.96)$ \\
\hline \multicolumn{4}{|l|}{ Birth interval } \\
\hline$<24$ months & $811(16.33)$ & $346(42.66)$ & 465 (57.34) \\
\hline$>=24$ months & $4,160(83.67)$ & $1,487(35.75)$ & $2,673(64.25)$ \\
\hline \multicolumn{4}{|l|}{ Type of birth } \\
\hline Single & $4,863(97.83)$ & 1,770 (36.39) & $3,093(63.61)$ \\
\hline Multiple & $108(2.17)$ & $62(57.41)$ & $46(42.59)$ \\
\hline \multicolumn{4}{|c|}{ Maternal education } \\
\hline No education & $2,665(53.60)$ & 1,111 (41.68) & $1,154(58.32)$ \\
\hline Primary & 1,759 (35.39) & $621(35.30)$ & $1,138(64.70)$ \\
\hline Secondary & $366(7.37)$ & 70 (19.13) & $296(80.87)$ \\
\hline Higher & $181(3.65)$ & $31(17.13)$ & $150(82.87)$ \\
\hline \multicolumn{4}{|l|}{ Wealth index } \\
\hline Poorest & $1,140(22.97)$ & $486(42.63)$ & 654 (57.37) \\
\hline Poorer & 1,098 (22.09) & 426 (38.79) & $672(61.21)$ \\
\hline Middle & 933 (18.78) & 395 (42.34) & $538(57.66)$ \\
\hline Richer & $880(17.72)$ & 317 (36.02) & $563(63.98)$ \\
\hline Richest & $917(18.46)$ & $207(22.57)$ & $710(77.43)$ \\
\hline
\end{tabular}




\begin{tabular}{|llll|}
\hline Variables & Total $\mathbf{n}(\%)$ & Stunted $\mathbf{n}(\%)$ & Normal $\mathbf{n}(\%)$ \\
\hline Residence & & & \\
Urban & $1,249(25.12)$ & $320(25.62)$ & $929(74.38)$ \\
Rural & $3,722(74.88)$ & $1,512(40.62)$ & $2,210(59.38)$ \\
Tigray & & & \\
Afar & $351(7.06)$ & $172(49.00)$ & $179(51.00)$ \\
Amhara & $74(1.50)$ & $32(43.24)$ & $42(56.76)$ \\
Oromia & $957(19.25)$ & $391(40.86)$ & $566(59.14)$ \\
Somali & $1,978(39.70)$ & $707(35.74)$ & $1,271(64.26)$ \\
b/gumz & $343(6.91)$ & $105(30.61)$ & $238(69.39)$ \\
SNNPR & $58(1.18)$ & $24(41.38)$ & $34(58.62)$ \\
Gambela & $1,007(20.27)$ & $366(36.35)$ & $641(63.65)$ \\
Harari & $21(0.43)$ & $4(19.05$ & $17(80.95)$ \\
Addis ababa & $14(0.29)$ & $5(35.71)$ & $9(64.29)$ \\
Dire dawa & $138(2.78)$ & $19(13.77)$ & $119(86.23)$ \\
\hline
\end{tabular}

\section{Spatial distribution of stunting in Ethiopia}

The study reveals the spatial distribution of childhood stunting in Ethiopia was non-random. The output from Global autocorrelation statistics shows spatial clustering of stunting with Moran's I index 0.37, Z score of 8.2 , and $P$-value $<0.01$. The positive $Z$ score and the minimum p-value indicate that there is less than $1 \%$ likelihood that the observed clustering was the result of random chance. The Getis-Ord hot spot analysis identifies hot spots (areas where high cases are surrounded by high cases) and cold spot areas (where low cases are surrounded by low cases). Hot spot clusters were observed in the Amhara region (East Gojam, North and South Gondar zones and South Wollo zone), and in the SNNP region (Sidama, Wolayta, Hadiya, and Gamo Gofa zones). Figure 1 shows the spatial distributions of stunting in Ethiopia.

\section{Sat scan analysis of stunting in Ethiopia}

From the output of Sat scan analysis, one big primary cluster containing 61 locations and 6 small nonsignificant clusters was identified. The primary cluster was located in the Amhara region (North and South Gondar zones and South Wollo zone), South Tigray zone, and in Afar regional state. The spatial window of the primary cluster was centered at $11.818783 \mathrm{~N}, 39.955788 \mathrm{E}$ with a $279.39 \mathrm{~km}$ radius, the relative risk of 1.50 , and the log-likelihood ratio of 42.97 at $P$-value $<0.001$. This means children living in 
this cluster $50 \%$ more likely stunted when compared with those living outside the cluster. The $p$-value is significant enough to conclude that this cluster was not the result of random chance. Figure 2 shows the output from Sat scan analysis of childhood stunting in Ethiopia.

\section{Multilevel analysis}

\section{The measure of variation (random effect) and model fitness}

As shown in Table 2, the null model (Model 1) revealed statistically significant variation in childhood stunting across communities (community variance $=0.436, \mathrm{P}<0.001$ ), in which $11.7 \%$ of the variation in the odds of childhood stunting is attributed to the community level factors (ICC=11.7\%).

Table 2

Random effect and model fitness showing the influence of community characteristics on childhood stunting in Ethiopia, EMDHS 2019

\begin{tabular}{|c|c|c|c|c|}
\hline Parameter & Model $1^{a}$ & Model $2^{b}$ & Model $3^{c}$ & Model $4^{\mathrm{d}}$ \\
\hline \multicolumn{5}{|l|}{ Random effects } \\
\hline Variance (SE) & $0.436(0.068)^{\star}$ & $0.326(0.058)^{\star}$ & $0.191(0.042)^{\star}$ & $0.166(0.041)^{\star}$ \\
\hline PCV (\%) & Reference & 25.2 & 56.2 & 61.9 \\
\hline ICC (\%) & 11.7 & 9.1 & 5.5 & 4.8 \\
\hline MOR & 1.88 & 1.72 & 1.52 & 1.47 \\
\hline \multicolumn{5}{|l|}{ Model fit statistics } \\
\hline DIC(-2log likelihood) & 6,462 & 6,130 & 6,330 & 6,042 \\
\hline \multicolumn{5}{|c|}{$\begin{array}{l}\text { SE Standard Error, PCV Proportional Change in Variance, ICC Intra-class Correlation Coefficient, MOR } \\
\text { Median Odds Ratio, DIC Deviation Information Criteria }\end{array}$} \\
\hline \multicolumn{5}{|c|}{ a Model 1 is an empty model, a baseline model without any explanatory variable } \\
\hline \multicolumn{5}{|c|}{${ }^{\mathrm{b}}$ Model 2 is adjusted for individual-level factors } \\
\hline \multicolumn{5}{|c|}{${ }^{\mathrm{C}}$ Model 3 is adjusted for community-level factors } \\
\hline \multicolumn{5}{|c|}{${ }^{\mathrm{d}}$ Model 4 is adjusted for individual and community-level factors } \\
\hline
\end{tabular}

After adjusting the model for individual-level factors (Model 2), the variation in the odds of childhood stunting remained statistically significant (community variance $=0.326, P<0.001$ ) across the communities, with $9.1 \%$ of the variance in the odds of childhood stunting could be attributed to the community-level factors 
Model 3, which is adjusted for community-level factors, revealed a statistically significant variance of childhood stunting (community variance $=0.191, \mathrm{P}<0.001$ ) across the communities. In this model, the community-level factors explained $56 \%$ of the variability in the odds of childhood stunting (PCV $=56.2 \%$ ), and $5.5 \%$ of the variation among the clusters was attributed to community-level factors (ICC $=5.5 \%$ ).

The final model (model 4), which adjusted for both individual and community-level factors simultaneously, depicted statistically significant variability to the odds of a child being stunted (community variance $=0.166, \mathrm{P}<0.001$ ). In this model, about $5 \%$ of the variability among communities in the odds of a child being stunted was due to the community-level factors (ICC $=4.8 \%$ ) and about $70 \%$ of the variance in the odds of childhood stunting (PCV $=61.9 \%)$ across communities was attributed to both individual and community-level factors.

Moreover, the MOR confirmed that childhood stunting was attributed to community-level factors. The MOR for stunting was 1.88 in the empty model; this indicated that there is variation between communities (clustering) since MOR is greater than the reference $(M O R=1)$. The unexplained community variation in stunting decreased to a MOR of 1.47 when all factors were added to the null model (empty model). This shows that when all factors are considered, the effect of clustering is still statistically significant in the full model. Regarding model fitness, the final model (incorporate both individual and community level factors) was the best-fitted model for this data since it had the lowest deviance.

\section{Factors associated with childhood stunting}

The results of multilevel logistic regression models for individual and community-level factors are presented in Table 3. In the final model, where all individual and community level factors are included child sex, child age, birth interval, type of birth, mother educational status, wealth index, and region were factors significantly associated with childhood stunting. 
Table 3

Multivariable multilevel logistic regression analysis of factors associated with childhood stunting in Ethiopia, EMDHS 2019

\begin{tabular}{|c|c|c|c|}
\hline Variables & $\begin{array}{l}\text { Model } 2 \\
\text { AOR }(95 \% \mathrm{Cl})\end{array}$ & $\begin{array}{l}\text { Model } 2 \\
\text { AOR }(95 \% \mathrm{Cl})\end{array}$ & $\begin{array}{l}\text { Model } 2 \\
\text { AOR }(95 \% \mathrm{Cl})\end{array}$ \\
\hline \multicolumn{4}{|c|}{ Individual-level factors } \\
\hline \multicolumn{4}{|c|}{ Age of a child (months) } \\
\hline $6-11$ & 1.00 & & 1.00 \\
\hline $12-23$ & $2.37(1.91-2.94)$ & & $2.36(1.90-2.92)^{\star \star \star}$ \\
\hline $24-35$ & $3.75(3.04-4.62)$ & & $3.74(3.04-4.59)^{\star \star \star}$ \\
\hline $36-47$ & 3.07 (2.49-3.79) & & $3.05(2.47-3.76)^{\star * \star}$ \\
\hline $48-59$ & $2.79(2.27-3.44)$ & & $2.78(2.26-3.43)^{\star \star \star}$ \\
\hline \multicolumn{4}{|l|}{ Child sex } \\
\hline Female & 1.00 & & 1.00 \\
\hline Male & $1.19(1.05-1.35)$ & & $1.21(1.06-1.37)^{\star \star}$ \\
\hline \multicolumn{4}{|l|}{ Birth interval } \\
\hline$>=24$ months & 1.00 & & 1.00 \\
\hline$<24$ months & $1.25(1.06-1.48)$ & & $1.30(1.11-1.53)^{\star \star}$ \\
\hline \multicolumn{4}{|l|}{ Type of birth } \\
\hline Single & 1.00 & & 1.00 \\
\hline Multiple & $2.45(1.61-3.73)$ & & $2.46(1.62-3.74)^{\star \star \star}$ \\
\hline \multicolumn{4}{|c|}{ Maternal education } \\
\hline No education & 1.00 & & 1.00 \\
\hline Primary & $0.98(0.85-1.14)$ & & $1.00(0.86-1.18)$ \\
\hline Secondary & $0.60(0.45-0.80)$ & & $0.63(0.47-0.84)^{* *}$ \\
\hline Higher & $0.52(0.35-0.77)$ & & $0.55(0.38-0.82)^{\star \star}$ \\
\hline
\end{tabular}

AOR adjusted odds ratio, $\mathrm{Cl}$ confidence interval, $1.00=$ reference ${ }^{*} \mathrm{P}<0.05,{ }^{* \star} \mathrm{P}<0.01{ }^{* \star *} \mathrm{P}<0.001$ 


\begin{tabular}{|c|c|c|c|}
\hline \multirow[t]{2}{*}{ Variables } & Model 2 & Model 2 & Model 2 \\
\hline & AOR $(95 \% \mathrm{Cl})$ & AOR (95\% Cl) & AOR (95\% Cl) \\
\hline \multicolumn{4}{|l|}{ Wealth index } \\
\hline Richest & 1.00 & & 1.00 \\
\hline Richer & $1.91(1.48-2.47)$ & & $1.75(1.29-2.36)^{\star \star \star}$ \\
\hline Middle & $2.27(1.75-2.95)$ & & $2.01(1.46-2.76)^{\star \star \star}$ \\
\hline Poorer & $1.98(1.52-2.56)$ & & $1.84(1.34-2.52)^{\star \star \star}$ \\
\hline Poorest & $2.08(1.62-2.67)$ & & $2.00(1.46-2.73)^{\star \star \star}$ \\
\hline \multicolumn{4}{|c|}{ Community-level factors } \\
\hline \multicolumn{4}{|l|}{ Residence } \\
\hline Urban & & 1.00 & 1.00 \\
\hline Rural & & $1.78(1.42-2.22)$ & $1.07(0.81-1.40)$ \\
\hline \multicolumn{4}{|l|}{ Region } \\
\hline Addis ababa & & 1.00 & 1.00 \\
\hline Tigray & & $4.08(2.43-6.79)$ & 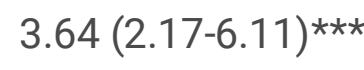 \\
\hline Afar & & $3.01(1.82-4.99)$ & $2.02(1.19-3.39)$ ** \\
\hline Amhara & & $2.88(1.73-4.78)$ & $2.29(1.37-3.86)^{\star \star}$ \\
\hline Oromia & & $2.18(1.33-3.59)$ & $1.58(0.95-2.64)$ \\
\hline Somali & & $1.69(1.02-2.84)$ & $1.02(0.60-1.74)$ \\
\hline Benishangul Gumz & & $2.58(1.54-4.34)$ & $1.87(1.10-3.17)^{*}$ \\
\hline SNNPR & & $2.25(1.36-3.72)$ & $1.62(0.97-2.72)$ \\
\hline Gambela & & $0.90(0.53-1.16)$ & $0.69(0.39-1.20)$ \\
\hline Harari & & $2.16(1.29-3.59)$ & $1.95(1.17-3.25)^{\star}$ \\
\hline Dire dawa & & $1.59(0.94-2.68)$ & $1.45(0.84-2.39)$ \\
\hline
\end{tabular}

\section{Individual-level factors}

Children aged 24-35 months old were 3.74 times (AOR $=3.74 ; 95 \% \mathrm{Cl}: 3.04-4.59)$ more likely to be stunted than children less than one-year-old. The odds of stunting were increased by $21 \%(A O R=1.21$; 
$95 \%$ Cl: 1.06-1.37) in male children compared to females. Children with mothers who completed higher education were $45 \%(\mathrm{AOR}=0.55 ; 95 \% \mathrm{Cl}$ : 0.38-0.82) less likely to be stunted compared to those children whose mothers had no formal education. Children with multiple birth types were 2.46 times (AOR $=2.46 ; 95 \% \mathrm{Cl}: 1.62-3.74)$ more likely to be stunted than children with single birth types. The odds of stunting were $30 \%$ higher among children with a shorter ( $<24$ months) birth interval compared to children with a longer birth interval ( $\geq 24$ months) ( $A O R=1.30 ; 95 \% \mathrm{Cl}: 1.11-1.53)$. Children from the poorest wealth quintile were 2 times $(A O R=2.00 ; 95 \% \mathrm{Cl}: 1.46-2.73)$ more likely to be stunted than children from the richest wealth quintile.

\section{Community-level factors}

Children living in Tigray (AOR =3.64; 95 \% Cl: 2.17-6.11), Afar (AOR 2.02; $95 \% \mathrm{Cl} 1.19-3.39$ ), Amhara (AOR $=2.29 ; 95 \% \mathrm{Cl}: 1.37-3.86)$, Benishangul Gumz (AOR=1.87; 95\% Cl: 1.10-3.17) and Harari $(A O R=1.95 ; 95 \% \mathrm{Cl}: 1.17-3.25)$ regions were more likely to be stunted compared to children living in Addis Ababa.

\section{Discussion}

This study determined the spatial distribution of stunting and its associated factors among children under the age of five in Ethiopia. The prevalence of childhood stunting is $37 \%$, indicating that stunting remains a serious public health challenge in Ethiopia. This study found that there is considerable spatial variation in childhood stunting in Ethiopia. Independent factors associated with childhood stunting in this study were child sex, child age, birth interval, birth type, wealth index, maternal education, and administrative region.

In this study, the local cluster analysis (Get-Ordi G*) identified childhood stunting hotspots and cold spot areas in the country. Hotspot clusters have been observed in the Amhara region (East Gojam, North and South Gondar, and South Wollo zones) and the SNNP region (Sidama, Wolayta, Hadiya, and Gamo Gofa zones). This finding is consistent with previous studies conducted on 2011 and 2016 EDHS datasets [17, 18]. This indicates that although the country is moving towards reducing childhood stunting, no significant changes have been observed in reducing the problem burden in certain areas. Therefore, identified clusters may be areas of preference for childhood stunting prevention and control interventions [19].

The Sat scan analysis is used to determine the true geographical location of clusters and to test whether these clusters are statistically significant. The output from this analysis identified one big primary cluster that contains 61 enumeration areas. The primary cluster was located in the Amhara region (North and South Gondar zones and South Wollo zone), South Tigray zone, and Afar region. This finding is similar to the hot spot analysis result of previous studies conducted in the same area $[17,18,20]$. Geographical and climatic factors may have contributed to the high incidence of childhood stunting in these areas. These areas are known for their acidity and are not suitable for crop production. This can lead to food shortages and hunger in a society where children are most affected. 
This study found that childhood stunting was significantly associated with child age; as the child gets older, the risk of stunting also increases. This finding is in line with studies in Bangladesh, Madagascar, and Malawi [21-23]. The possible explanation for this could be due to the inappropriate and late introduction of low nutritional quality supplementary food [24] and a large portion of guardians in rural areas are ignoring to meet their children's optimal food requirements as the age of the child increases [25].

The current study also determined that males are more likely to be stunted than females. This result is consistent with previous studies conducted in sub-Saharan Africa [26-28]. This may be due to preferences in feeding methods or other forms of exposure [26]. Nutritional status can be defined as "biological instability" because boys are expected to grow faster than girls and their growth is easily affected by a lack of healthy food or other diseases or risks [29]. Gender differences in stunting are common in areas of stress caused by ongoing infection and exposure to toxins and air pollution [30]. Furthermore, the proportion of male premature births is higher than that of female premature births, which also contributes to childhood stunting [31-33].

Maternal education has been found to be negatively associated with childhood stunting. Consistently, previous studies shows that maternal education has a positive outcome in reducing childhood stunting [34-39]. The knowledge that mothers acquire from formal education can help them to develop important nutrition and hygiene behaviours that prevent childhood stunting. Another reason is that educated mothers have a tendency to seek better health for childhood illnesses than uneducated mothers, which can prevent stunting $[40,41]$. Therefore, maternal education is an important strategy to develop intelligent eating habits in young children and to overcome the growing burden of childhood stunting.

The current findings show that children from poorest quintile families are more likely to be stunted than children with richest wealth. This result is consistent with previous studies conducted in various developing countries [34,42-44]. This might be attributed to the fact that increased income improves food diversity, improving nutrient intake and nutritional status $[45,46]$. In addition, providing children with well-nourished, timely medical care from wealthy families reduces their chances of stunting if they have an infection. Therefore, it is necessary to establish an appropriate financial and economic framework that supports the children of disadvantaged families, such as improving child health, improving food security, and accessing basic health care services.

This study found that having a birth interval $\geq 24$ months reduce the chance of being stunted. This is consistent with other studies $[47,48]$. Short birth intervals can adversely affect child nutrition due to delayed uterine development, and/or reduced childcare quality [49]. The present study alsoconfirmed that children in the Amhara, Benishangul, and Tigray regions are more stunted than children in Addis Ababa. This finding is similar to other research in Ethiopia [17], Congo [50], and Nigeria [51]. This difference may be attributed to the socio-economic and education disparities and access to basic Healthcare facilities. This difference is due to socio-economic and educational inequalities and access to basic health care 
facilities. Therefore, contextualized interventions are essential in the fight against childhood stunting and improved health, especially for developing and rural areas.

This study is important to identify the underlying factors related to childhood stunting to plan public health interventions and contribute to the appropriate allocation of resources and health services. In addition, it helps the Ethiopian government to design and implement appropriate nutrition programs aimed at improving maternal and child nutrition at the individual and community levels, especially in developing and rural areas.

\section{Strengths and limitations}

The strength of this study is that it used nationally representative survey data. Another important strength of this study is the use of multilevel logistic regression analysis, which can detect factors other than individual-level factors that cannot be detected using standard logistic regression analysis. Furthermore, the use of a combination of methods (spatial and regression statistics) is a force that allows the validation of identified hotspot areas due to the predictions of statistical methods. On the other hand, the limitation of this study is that we were unable to establish a cause-and-effect relationship due to the cross-sectional nature of the study design. Another limitation is the use of secondary data that limits the ability to include other variables such as behavioral factors and dietary factors related to childhood stunting.

\section{Conclusion}

Statistically significant-high hotspots have been found in the northern parts of Ethiopia. Both individual and community-level factors determined childhood stunting. Being male, increased age of the child, short birth interval, multiple births, no formal education of mother, and being from a household in the lowest wealth quintile were the factors that increased the odds of stunting at the individual level. At the community level, children in the Amhara, Tigray, and Benishangul communities are more likely to suffer from stunting than children in Addis Ababa. Therefore, improving the nutritional status of children requires the intervention of multiple factors such as reducing poverty, ensuring adequate birth intervals, and providing education to mothers. Areas, where childhood stunting is high, should be identified for healthy eating interventions.

\section{Abbreviations}

AOR: adjusted odds ratio; Cl: confidence intervals; EMDHS: Ethiopian mini demographic health survey; GIS: geographic information system; HAZ: height-for-age; ICC: intra-cluster correlation; MOR: median odds ratio; PCV: proportional change in variance; SD: standard deviation; WHO: world health organization.

\section{Declarations}




\section{Ethics approval and consent to participate}

Since this study is a secondary data analysis of publicly available survey data from the DHS program, this particular study does not require ethical approval and participant consent. We requested the DHS program and allowed us to download and use data for this study from http://www.dhsprogram.com.

\section{Consent for publication}

Not applicable.

\section{Availability of data and materials}

The dataset we used for this study are publicly available in the MEASURE DHS Program and you can access it from www.measuredhs.com once you have explained the objectives of the study. Upon receipt of the Authorization Letter, the data will be accessed and downloaded for free.

\section{Competing interest}

The authors declare that they have no competing interest.

\section{Funding}

The authors received no specific funding for this study.

\section{Authors' contributions}

DEY, BTS, and ES conceived the study, conducted the data analysis and interpretation. GAT, SH, ADD, and ESA assisted the data analysis and interpretation. DEY drafted the manuscript with input from all authors. All authors have a substantial contribution in revising and finalizing the manuscript. All authors read and approved the final version of the manuscript.

\section{Acknowledgements}

We would like to thank the DHS program, for providing the dataset used in this study.

\section{References}


1. WHO. Stunting in a nutshell [Internet]; 2015. Podcast. Available from: https://www.who.int/news/item/19-11-2015-stunting-in-a-nutshell.

2. Victora CG, Adair L, Fall C, Hallal PC, Martorell R, Richter L, Sachdev HS, Maternal and Child Undernutrition Study Group. Maternal and child undernutrition: consequences for adult health and human capital. Lancet. 2008;371(9609):340-57.

3. Black RE, Allen LH, Bhutta ZA, Caulfield LE, deOnis M, Ezzati M, et al. Maternal and child undernutrition: global and regional exposures and health consequences. Lancet. 2008;371:243-60.

4. UNICEF W, World bank, . Levels and trends in child malnutrition. Geneve; 2019.

5. Ethiopian Public Health Institute (EPHI) [Ethiopia] and ICF. 2021. Ethiopia Mini Demographic and Health Survey 2019: Final Report. Rockville, Maryland, USA: EPHI and ICF.

6. Sisay FT, Sh Z, Lema M, Wubarege S. Prevalence and associated factors of stunting among 6-59 months children in pastoral Community of Korahay Zone, Somali regional state, Ethiopia. J Nutr Disord Ther. 2017. .

7. Amare D, Negassie A, Tsegaye B, Assefa B, Ayenie B. Prevalence of undernutrition and its associated factors among children below five years of age in bure town, west Gojjam zone, Amhara National Regional State, Northwest Ethiopia. Adv Public Health. 2016.

8. Ikeda N, Irie Y, Shibuya K. Determinants of reduced child stunting in Cambodia: analysis of pooled data from three demographic and Health surveys. Bull World Health Organ. 2013;91(5):3419. https://doi.org/10.2471/BLT.12.113381.

9. Agho KE, Inder KJ, Bowe SJ, Jacobs J, Dibley MJ. Prevalence and risk factors for stunting and severe stunting among under-fives in North Maluku province of Indonesia. BMC Pediatr. 2009;10:1-10.

10. Mzumara B, Bwembya P, Halwiindi H, Mugode R, Banda J. Factors associated with stunting among children below five years of age in Zambia: evidence from the 2014 Zambia demographic and health survey. BMC Nutr. 2018;4:1-8.

11. Nshimyiryo A, Hedt-gauthier B, Mutaganzwa C, Kirk CM, Beck K, Ndayisaba A, et al. Risk factors for stunting among children under five years : a crosssectional population-based study in Rwanda using the 2015 Demographic and Health Survey. BMC Public Health. 2019;19:1-10.

12. WHO (World Health Organization), UNICEF. Global Nutrition monitoring framework. Operational guidance for tracking progress in meeting targets for 2025. 2017:1-82. Available from: http://apps.who.int/iris/bitstream/handle/10665/259904/9789241513609eng.pdf;jsessionid=82B08433379C3E3E69B3F8D4F2690C34? sequence $=1 \% 0$ Awww.who.int/nutrition.

13. World Health Organization. Sixty-Fourth World Health Assembly. Wha64/2011/Rec/1; 2011. p. 1624. Available from: http://scholar.google.com/scholar?hl=en\&btnG=Search\&q=intitle:SIXTYFOURTH+WORLD+HEALTH+ASSEMBLY\#1\%5Cn http://scholar.google.com/scholar? $\mathrm{hl}=$ en\&btnG=Search\&q=intitle:Sixty-fourth+World+Health+Assembly\%231.

14. WHO. Maternal, infant and young child nutrition Comprehensive implementation plan on maternal, infant and young child nutrition: biennial report Report by the Director-General. In: Exec Board 142nd 
Sess provisional agenda item46, vol. 3; 2018. p. 1-8. Available from: http://www.who.int/nutrition/gina/en/.

15. Government of Ethiopia. National Nutrition Program 2016-2020; 2016. p. 88. Available from: www.unicef.org/ethiopia/National_Nutrition_Programme.pdf.

16. Esri, ArcGIS®Desktop 10.7: ArcMap ${ }^{\text {TM }}$ Functionality Matrix. 2019, Esri: USA.

17. Hailu BA, Bogale GG, Beyene JJSr. Spatial heterogeneity and factors influencing stunting and severe stunting among under-5 children in Ethiopia: spatial and multilevel analysis. 2020;10(1):1-10.

18. Alemu ZA, Ahmed AA, Yalew AW, Birhanu BS. Non random distribution of child undernutrition in Ethiopia: spatial analysis from the 2011 Ethiopia demographic and health survey. International Journal for Equity in Health. 2016;15(1):198.

19. Khamis FG, El-Refae GA. Association between Spatial Patterns of Acute Malnutrition and Household Income in Iraq-2004. Int J Statistics Probability. 2012;1(1):43-52.

20. Haile D, Azage M, Mola T, Rainey R. Exploring spatial variations and factors associated with childhood stunting in Ethiopia: spatial and multilevel analysis. BMC Pediatrics. 2016;16(1):49.

21. Kamal S. Socio-economic determinants of severe and moderate stunting among under-five children of rural Bangladesh. Mal J Nutr. 2011;17(1):105-18.

22. Rakotomanana H, Gates GE, Hildebrand D, Stoecker BJ. Determinants of stunting in children under 5 years in Madagascar. Matern Child Nutr. 2016: e12409. https://doi.org/10.1111/mcn.12409.

23. Ntenda PAM, Chuang Y-C. Analysis of individual-level and community-level effects on childhood undernutrition in Malawi. Pediatr Neonatol. 2017;59: 380-9.

24. Dasgupta A, Parthasarathi R, Biswas R, Geethanjali A. Assessment of under nutrition with composite index of anthropometric failure (CIAF) among under-five children in a rural area of West Bengal. Indian J Community Health. 2014;26(2):132-8.

25. Khan REA, Raza MA. Determinants of malnutrition in Indian children: new evidence from IDHS through CIAF. Qual Quant. 2016;50(1):299-316.

26. Wamani H, Åstrøm AN, Peterson S, Tumwine JK, Tylleskär T. Boys are more stunted than girls in subSaharan Africa: a meta-analysis of 16 demographic and health surveys. BMC Pediatr. 2007;7(1):17.

27. García Cruz LM, González Azpeitia G, Reyes Súarez D, Santana Rodríguez A, Loro Ferrer JF, SerraMajem L. Factors associated with stunting among children aged 0 to 59 months from the central region of Mozambique. Nutrients. 2017;9(491):1-16. https://doi.org/10.3390/nu9050491.

28. Bukusuba J, Kaaya A, Atukwase A. Predictors of Stunting in Children Aged 6 to 59 Months: A CaseControl Study in Southwest Uganda. Food Nutr Bull. 2017. https://doi.org/10.1177/0379572117731666.

29. Condo JU, Gage A, Mock N, Rice J, Greiner T. Sex differences in nutritional status of HIV-exposed children in Rwanda: a longitudinal study. Trop Med Int Health. 2015;20(1):17-23.

30. Olack B, Burke H, Cosmas L, Bamrah S, Dooling K, Feikin DR, et al. Nutritional status of under-five children living in an informal urban settlement in Nairobi, Kenya. J Health Popul Nutr. 
2011;29(4):357.

31. Elsmen E, Hansen Pupp I, Hellstrom-Westas L. Preterm male infants need more initial respiratory and circulatory support than female infants. Acta Paediatrica. 2004;93(4):529-33.

32. Escobar GJ, Clark RH, Greene JD. Short-term outcomes of infants born at 35 and 36 weeks gestation: we need to ask more questions. Semin Perinatol. 2006;30(1):28-33.

33. Kilbride HW, Daily DK. Survival and subsequent outcome to five years of age for infants with birth weights less than 801 grams born from 1983 to 1989. J Perinatology. 1998;18(2):102-6.

34. Kabubo-Mariara J, Ndenge GK, Mwabu DK. Determinants of children's nutritional status in Kenya: evidence from demographic and health surveys. J African Economies. 2009;18:363-87.

35. Adekanmbi VT, Kayode GA, Uthman OA. Individual and contextual factors associated with childhood stunting in Nigeria: a multilevel analysis. Matern Child Nutr. 2013;9(2):244-59.

36. Keino S, Plasqui G, Ettyang G, van den Borne B. Determinants of stunting and overweight among young children and adolescents in sub-Saharan Africa. Food Nutr Bull. 2014;35(2):167-78.

37. Semba RD, de Pee S, Sun K, Sari M, Akhter N, Bloem MW. Effect of parental formal education on risk of child stunting in Indonesia and Bangladesh: a cross-sectional study. Lancet. 2008;371(9609):322-8.

38. Makoka D. The Impact of Maternal Education on Child Nutrition: Evidence from Malawi, Tanzania, and Zimbabwe. DHS working Papers. 2013;84.

39. Urke HB, Bull T, Mittelmark MB. Socioeconomic status and chronic child malnutrition: Wealth and maternal education matter more in the Peruvian Andes than nationally. Nutrition Res. 2011;31(10):741-7.

40. Tessema F, Asefa M, Ayele F. Mothers' Health Services Utilization and Health Care Seeking Behavior During Infant Rearing: A Longitudinal Community Based Study, South West Ethiopia. Ethiopian J Health Development. 2002;16:51-8.

41. Assefa T, Belachew T, Ayalew T, Deribew A. Mothers' Health Care Seeking Behavior For Childhood Illnesses In Derra District, Northshoa Zone, Oromia Regional State, Ethiopia. Ethiopian J Health Development. 2008;18(3):90-3.

42. Hong R, Banta JE, Betancourt JA. Relationship between household wealth inequality and chronic childhood under-nutrition in Bangladesh. Int J Equity Health. 2006;5:15.

43. Hong R, Mishra V. Effect of wealth inequality on chronic under-nutrition in Cambodian children. J Health Popul Nutr. 2006;24(1):89-99.

44. Hong R. Effect of economic inequality on chronic childhood undernutrition in Ghana. Public Health Nutr. 2007;10(4):371-8.

45. Taruvinga A, Muchenje V, Mushunje A: Determinants of rural household dietary diversity: The case of Amatole and Nyandeni districts, South Africa. International Journal of Development and Sustainability. 2013;2(4):1-15. 
46. Doan D. Does income growth improve diet diversity in China?Selected Paper prepared for presentation at the 58 the AARES Annual Conference, Port Macquarie, New South Wales. 2014.

47. Gribble JN, Murray NJ, Menott EP. Reconsidering childhood undernutrition: can birth spacing make a difference? An analysis of the 2002-2003 El Salvador National Family Health Survey. Matern Child Nutr. 2008;5(1):49-63.

48. Ikeda N, Irie Y, Shibuya K. Determinants of reduced child stunting in Cambodia: analysis of pooled data from three Demographic and Health Surveys. Bull World Health Organ. 2013;91:341-9.

49. Dewey KG, Cohen RJ. Does birth spacing affect maternal or child nutritional status? A systematic literature review. Maternal Child Nutrition. 2007;3:151-73.

50. Kandala N-B, Madungu TP, Emina JB, Nzita KP, Cappuccio FP. Malnutrition among children under the age of five in the Democratic Republic of Congo (DRC): does geographic location matter? BMC Public Health. 2011;11(1):261.

51. Akombi B, Agho KE, Hall JJ, Astell-Burt TE. Stunting and severe stunting among children under-5 years in Nigeria : A multilevel analysis. BMC Pediatr. 2017;17:1-6.

\section{Figures}




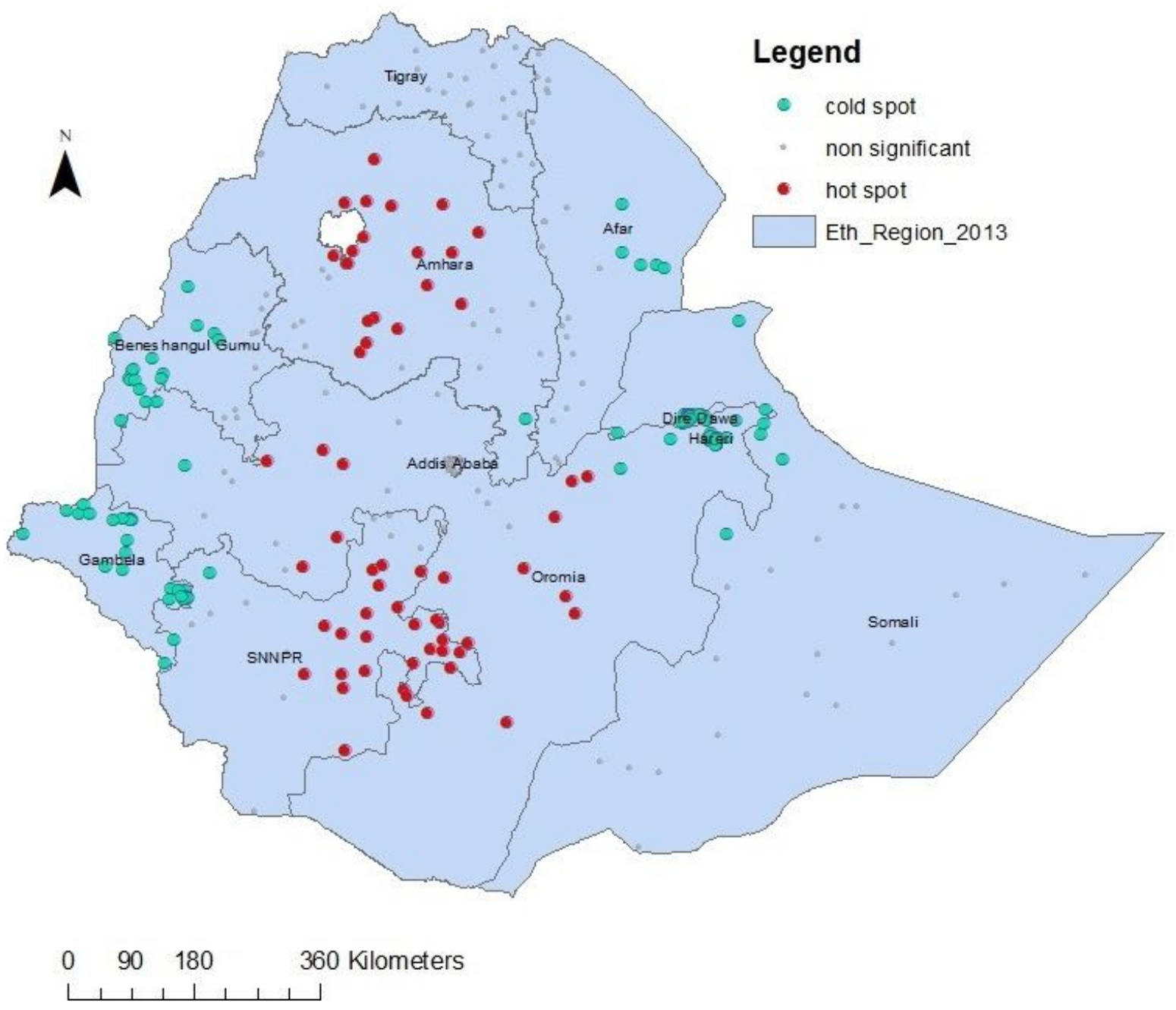

Figure 1

Spatial distributions of stunting in Ethiopia, EMDHS 2019 


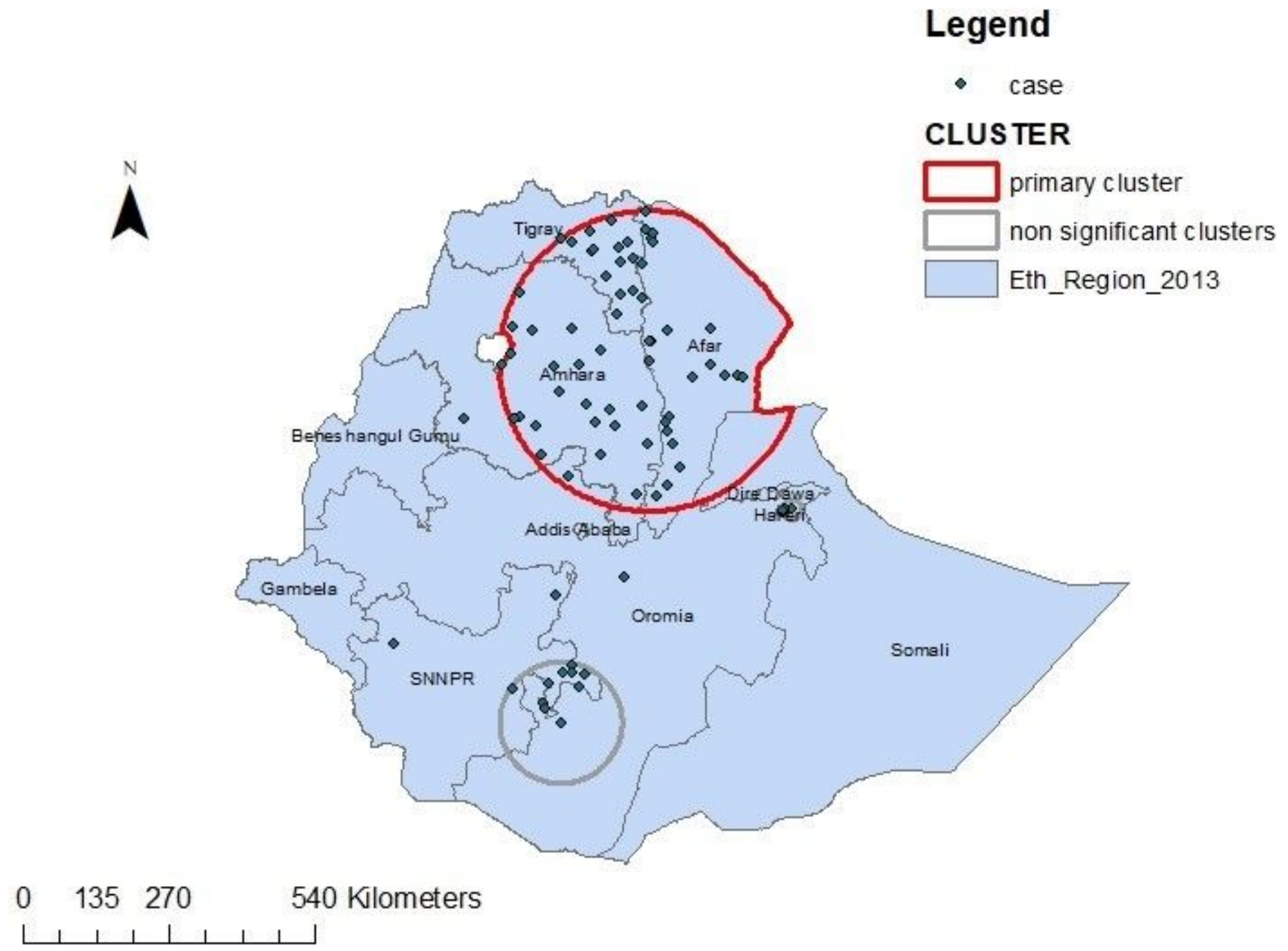

Figure 2

Sat scan analysis of childhood stunting in Ethiopia, EMDHS 2019 